\title{
Supporting Risk Assessment of Bt Cotton in Brazil: Synthesis and Recommendations
}

\author{
D.A. Andow, E.M.G. Fontes, A. Hilbeck, J. Johnston, \\ D.M.F. Capalbo, K.C. Nelson, E. Underwood, \\ G.P. FITT, E.R. SUJII, S. ARPAIA, A.N.E. BIRCH,
} A. Pallini and R.E. Wheatley

Corresponding author: Dr D.A. Andow, Professor of Insect Ecology, University of Minnesota, 219 Hodson Hall, 1980 Folwell Avenue, St Paul, MN 55108, USA. Fax: +1 612 6255299, e-mail: dandow@umn.edu

Transgenic crops have been promoted vigorously throughout the world as the most significant recent development of agricultural technology. They have, however, engendered greater controversy than any previous agricultural technology. This controversy has focused on two related issues: (i) how can they be used to help humankind and (ii) how can they be evaluated to avoid harming biodiversity and humankind? These controversies are acute in Brazil, where impassioned discussions have continued for over 10 years (Capalbo et al., Chapter 3, this volume).

In September 2003, the Cartagena Biosafety Protocol to the Convention on Biological Diversity entered into force. Among its several provisions, the protocol requires the use of a case-specific risk assessment to evaluate the environmental safety of a genetically engineered crop. Brazil is a party to the protocol, and has expressed considerable interest in developing the necessary expertise to conduct appropriate risk assessments.

This book focuses on the methods for conducting the science that supports environmental risk assessment of transgenic crops that are in the process of commercial development, using Bacillus thuringiensis $(\mathrm{Bt})$ cotton as a case study, and expands on results reported in Capalbo and Fontes (2004). Throughout this book, we have relied on publicly available data to instantiate the evaluations and methodologies. While there is considerably more data in the private sector, by relying on the publicly available data we could ensure that our evaluations were transparent and would reinforce the 
fact that we had not conducted an actual risk assessment of Bt cotton. Moreover, it should be appreciated that the validity of the methodologies to support risk assessment is not influenced by the absence of private-sector data. Several kinds of Bt cotton were considered, but the case study concentrated on two private-sector events - a Cry1Ac event and a combined Cry $1 \mathrm{Ac} / \mathrm{Cry} 2 \mathrm{Ab}$ event, targeted to control Lepidopteran pests (see Grossi et al., Chapter 4, this volume). We recognize that there are several other private-sector events being developed that Brazil may consider, and that Brazilian Agricultural Research Corporation (Embrapa) is developing their own Bt cotton events; we suggest throughout the book that the methodologies should readily generalize to these other events. In this chapter, we will briefly summarize the agricultural context for the possible use of Bt cotton in Brazil and some of the main findings of the previous chapters. We will finish the chapter by describing some of the broader implications from the case study and suggest activities to further develop the scientific capacities for environmental risk assessment of transgenic crops in Brazil.

\section{Cotton in Brazil and the Lepidopteran Pests}

Cotton is an important and expanding cash crop in Brazil, and is grown in a wide range of climates, soils and crop-production systems (Fontes et al., Chapter 2 , this volume). There are three main production regions: the North-east, the Meridian and the Midwest. Cotton production in Brazil has over 100 years of history, but in the last 5-10 years large areas of new agricultural land have been brought into production in the Midwest, where about $76 \%$ of the area of Brazilian cotton is now grown. This shift to the Midwest has moved cotton production to poorer soils with associated changes in the cropping system and environment, including higher fertilizer use, higher altitudes, double-cropping with millet and direct drilling of seeds under minimal tillage. New high-yielding varieties are used, but these tend to be susceptible to viral diseases. Production is predominantly under very large-scale mechanized monoculture, with high use of pesticides and growth regulators. It is one of the most productive rainfed cotton areas in the world, and accounts for $85 \%$ of Brazilian fibre production. At the same time, socio-economic factors and the severe damage of the recent boll weevil invasion since the mid 1980s have contributed to the decline in cotton production by small-scale farmers in the North-east and Meridian regions.

Damage caused by pests and diseases is one of the main constraints to cotton productivity. The boll weevil and the cotton aphid are the most significant arthropod pests in all cotton-growing regions of Brazil. Unchecked, the boll weevil can cause total crop failure by killing or damaging the cotton bolls. The cotton aphid causes direct damage to cotton, but is a key limiting factor to cotton production as a vector of viral diseases, particularly blue disease caused by a luteovirus (Corrêa et al., 2005). Particularly in the Midwest, where virus-susceptible varieties are widely grown, the risk of viral disease is prompting farmers to apply six to eight insecticide sprays to control cotton aphids from early in the growing season. 
The most important Lepidopteran pests on cotton are cotton leafworm (Alabama argillacea (Hübner)), pink bollworm (Pectinophora gossypiella (Saunders)), tobacco budworm (Heliothis virescens (Fabricius)) and fall armyworm (Spodoptera frugiperda (J.E. Smith)). In the North-east, the first two species are the main Lepidopteran pests. In the Meridian region, the tobacco budworm is also important, and in the Midwest all four species are important. Cotton leafworm and pink bollworm are found feeding only on cotton, and in Brazil tobacco budworm is mainly restricted to cotton. Fall armyworm is highly polyphagous and is also a pest of maize and sorghum, which are often grown near cotton. More up-to-date information on pest status, damage and yield loss are needed, and there is clearly the need for a concentrated effort to develop an integrated pest management (IPM) programme to address the entire pest complex in an integrated way, emphasizing farmer education and extension.

Accurate predictions on how much farmers will reduce insecticide applications on Lepidopteran-active $\mathrm{Bt}$ cotton are difficult to make due to the complexity and dynamic nature of Brazilian cropping systems, and the range and differing sensitivity to $\mathrm{Bt}$ of the pest Lepidoptera (Fitt et al., Chapter 12, this volume). The four target species differ markedly in host range and association with cotton. Bt cotton will not reduce insecticide use for boll weevil, but is likely to generate savings of $\sim 2$ pesticide applications for the target Lepidoptera (Fontes et al., Chapter 2, this volume; Fitt et al., Chapter 12, this volume). This would halve insecticide use in the North-east but only reduce it by $\sim 10 \%$ in the Meridian and Midwest regions, where large amounts of insecticide are applied to control boll weevil and cotton aphid. Under conditions of decreasing or low pesticide use, natural enemies of pests may become more abundant, possibly enabling integration with biological controls. This will be possible only on virus-resistant varieties and when there is no need to apply insecticides to control other early-season pests. Other options are the application of cultural control methods, the selection of appropriate cultivars and the enhancement of biological control. In particular, new approaches for the integrated control of the boll weevil and the aphid-transmitted blue disease are urgently needed.

\section{Problem Formulation and Options Assessment}

Problem formulation and options assessment (PFOA) serves as a cornerstone in support of environmental risk assessment for transgenic organisms. One of the greatest challenges is to understand the conflicted nature of the discussion about transgenic organisms in Brazilian society, while finding a common ground from which it is possible to move forward. PFOA enables this to occur and, in so doing, the authors (Capalbo et al., Chapter 3, this volume) reached several conclusions and reinforced findings of previous authors (Nelson et al., 2004). Perhaps the most robust conclusion about PFOA is that all of the authors, who represent all of the key decision-making authorities in Brazil, agreed that a PFOA would be useful for Brazil and that the process should be further designed to meet the needs of Brazil. 
PFOA proposes a deliberative process with multi-stakeholder participation and allows members of society to participate in the evaluation of critical needs and risks associated with transgenic organisms. It is best served if it is driven by sound, scientifically guided assessment and review. The purpose of a PFOA is to define the problem situation that is addressed by the transgenic organism under consideration and describe realistic options for addressing the problem situation. Thus, a PFOA specifies the context and scope for subsequent risk assessment and suggests alternatives to which a transgenic organism could be compared. These requirements imply that conducting a successful PFOA is a complex process - but this should not be considered as a possible argument against its use. Most important societal decisions are complex, messy and controversial, and because they are complex, messy and controversial we should work to improve them with transparent, systematic and scientifically based discussion. By doing so, the decision-making process gains social legitima$\mathrm{cy}$ and society gains greater confidence in the decisions taken. A PFOA can be used to provide such a discussion, and can play a significant role in environmental risk assessment.

Brazil has been working for nearly a decade to enact regulatory legislation, in part to provide the society adequate assurance that care and precaution will be taken to warrant both environmental and human health safety of all food/feed produced from transgenic organisms (see Capalbo et al., Chapter 3, this volume, for a full discussion). The PFOA would need to be situated within the Brazilian regulatory framework to be effective. At present, this is the new Brazilian Biosafety Law (Law no. 11.105, of March $24,2005)$ for transgenic organisms and their by-products that provides across-the-board regulation in the areas of agriculture, health and environment. Its provisions cover both authorizations for laboratory, greenhouse and field experiments and applications in fields such as forestry, bioremediation, agriculture and medicine. Inspection agencies and entities under the Ministry of Agriculture Cattle Raising and Supply, the Ministry for the Environment and the Ministry of Health are involved in inspections and enforcing penalties.

The National Technical Committee for Biosafety (CTNBio), which was created by Provisional Measures (PM) in 1996 and 2001, is given responsibility for assessment of health and environmental risks posed by transgenic organisms. Decisions of the CTNBio are sent to the above agencies; these agencies grant registrations and are responsible for monitoring in the respective areas. CTNBio shall rule, at the last and final jurisdiction, on cases when the activity involves a potential or effective agent of environmental degradation, and on the need for environmental licensing (Capalbo et al., Chapter 3, this volume). Despite the evolution of the regulatory system, the PFOA's charge may be best conducted under the umbrella of the CTNBio, mainly because Article 15 of the new Biosafety Law gives authority to CTNBio to carry out public hearings where civil society participation is assured under the terms of the law. The situation remains fluid because new regulations may modify the roles of the agencies involved, and it may be too early to try to link the PFOA to any particular agency. 
Some modifications will be necessary to make the PFOA responsive to multiple stakeholders. The CTNBio expert committee would need to be diversified to include expertise in economics, social science and broader areas of environmental science outside of agriculture. As the legal authority, the CTNBio would be able to charge a multi-stakeholder group to initiate a PFOA as a first step in risk assessment to help understand the problem, provide a preliminary review of options and highlight critical societal concerns. Then studies can be conducted during the subsequent stages in the development of a transgenic plant (Andow et al., Chapter 1, this volume). A second PFOA meeting should be conducted when laboratory and field environment biosafety test results can be included in the evaluation by the PFOA group. As a suggestion to those who will consider these ideas for implementation, the authors encourage the nation to develop systems for monitoring new technologies, and consider the PFOA methodology as an approach that can be adapted to postrelease monitoring as well as prerelease evaluation.

In general, the Brazilian evaluation of the PFOA methodology builds on the Kenyan case of Bt maize (Nelson et al., 2004) and confirms that this methodology is essential for assessing proposed uses of transgenic organisms because it provides constructive arenas for dialogue and potential consensus. Within Brazil it would need to be solidly anchored in the regulatory framework and needs to be structured to have greater emphasis on environmental concerns outside of agriculture in order to function successfully. Even in the highly politicized debates about Brazil's use of transgenic organisms, the authors (a diverse group of ministry officials) see some promise in the PFOA's guided discussion over a range of issues that enables societal consideration of a new transgenic organism. The next steps for designing and implementing a Brazilian PFOA require developing specifics of the multi-stakeholder process and consultation with a broader group of stakeholders.

\section{Transgene Expression and Locus Structure}

Characterizing transgene expression and locus structure provides the basic information necessary to conduct a risk assessment. The results and recommendations for Bt cotton (Grossi et al., Chapter 4, this volume) reinforce two key recommendations from a previous case study on $\mathrm{Bt}$ maize in Kenya (Andow et al., 2004). It is recommended that the transgene locus is sequenced with flanking regions in the plant to reduce the likelihood that the transgenic plant might produce unexpected or inadvertent (unintended) gene products. DNA sequencing of the transgene locus in the plant provides definitive scientific evidence for reducing uncertainties associated with the transgene locus, including ectopic expression, spurious open reading frames (ORFs), homologous recombination and disturbance of a native plant gene. Although this is not a requirement now in several national risk-assessment processes for transgenic plants, it is a technically feasible standard practice, and would be the easiest and most economical means to meet many regulatory standards. However, while DNA sequencing is necessary for risk assess- 
ment, it is not sufficient. It is also necessary to characterize the transgene phenotype. To do this, transgene expression should be measured in whole plants in the relevant environments in which they will be grown, because expression can vary among plant tissues, plant life stages and environmental conditions (such as soil types).

In this case study, we have focused on two Bt-cotton events. Publicly available information on these events was insufficient for risk-assessment purposes, lacking DNA sequence of the transgene locus and sufficient expression data from relevant plant tissues, growth stages and environments. Consequently, we focused primarily on methods to characterize the transgene locus and phenotype (Grossi et al., Chapter 4, this volume). We found that all of the aspects of characterizing the transgene (locus structure and expression) can be addressed with scientifically feasible experimental protocols. In addition, we suggested that while transformation purely for research purposes may use many marker genes and the entire Ti plasmid backbone, transformation for commercial use would be advised to eliminate marker genes and the $\mathrm{Ti}$ plasmid backbone and to select simple transformation events at single transgene loci for development.

\section{Non-Target and Biodiversity Effects}

Risks to non-target species and biodiversity are difficult to assess because there are many non-target species and they interact in complicated ways. In Chapters 5-10, we have elaborated a methodology to provide scientific data for non-target risk assessment (Andow and Hilbeck, 2004; Birch et al., 2004) that focuses on the species that are most at risk in the recipient environment. The objective of the methodology is to identify possible adverse effects and characterize risks to non-targets species and ecosystem processes in the environment of interest (Hilbeck et al., Chapter 5, this volume). This is done by choosing significant functional categories of species and ecosystem processes, screening species and ecological functions within those categories for possible risks, conducting an exposure assessment, identifying possible adverse effects, generating testable scientific hypotheses about how risks might occur and developing experiments to test these hypotheses.

For Bt cotton in Brazil, the authors chose to focus the assessment on nontarget cotton arthropod pests (Sujii et al., Chapter 6, this volume), pollinators, flower visitors, endangered Lepidoptera (Arpaia et al., Chapter 7, this volume), arthropod predators in cotton (Faria et al., Chapter 8, this volume), parasitoids of important cotton pests (Pallini et al., Chapter 9, this volume) and soil ecosystem processes (Mendonça et al., Chapter 10, this volume). These choices reflected an overall concern that Bt cotton could have adverse effects on cotton production, possibly offsetting its potential benefits. This could be particularly problematic for the small-scale farmers in the North-east and Meridian regions. Non-target pests might be released from insecticides, competition, predation or parasitism, pollination might be reduced and the incidence of aphid-vectored disease might be exacerbated. Soil health may be 
reduced. Except for endangered Lepidoptera, it was not possible to address adverse effects on surrounding natural areas, such as the Cerrado in the Midwest, systematically in this book. This needs to be revisited in the future.

Species that could be at risk were identified using a Species Selection Matrix and an Exposure Assessment Matrix, both of which were useful to screen species and processes to identify a short list of candidates for actual experimental testing. The first matrix screens on the basis of exposure to the crop and significance of the ecological function, and requires information only about the crop and the intended environment of introduction. The second matrix requires information about transgene expression in the plant. From a total of over 90 species, seven species and three species groups (ladybird beetles, green lacewings and earthworms) were prioritized as possible candidates for risk-assessment experiments in all three of the cotton-growing regions, and three species were considered important regionally (Table 13.1). Five soil ecosystem functions were prioritized (Table 13.1). Several chapters suggested that the process should give special weight to the diversity of feeding modes in prioritizing the species.

These procedures rely heavily on expert judgement that depends greatly on the working information and experiences of the experts. Because cotton has only recently expanded into the Midwest, there is relatively little information or experience on cotton ecology from this region. New baseline information from the Midwest is likely to expand the initial listing of species (Arpaia et al., Chapter 7, this volume), which may result in more species or a greater diversity of species being prioritized (see VI.2. below). The selection matrix also highlighted gaps of knowledge on the ecology of cotton, which can be used to prioritize the needs for baseline research. A precautionary approach to considering uncertainty was used (Hilbeck et al., Chapter 5, this volume). The soil micro-, meso- and macrofauna are so complex and little known that a species-based approach to risk assessment is infeasible. Although additional information about these soil organisms would be helpful, we avoided the problems inherent in this uncertainty by focusing on the ecosystem processes in relation to non-target risk assessment.

For the prioritized candidate species and functions, we identified potential adverse environmental effects and formulated experimentally testable hypotheses about potential exposure and adverse-effect scenarios. We designed experiments to refute or confirm the hypotheses. In most cases, experiments were aimed to estimate the effects of $\mathrm{Bt}$ cotton on fitness or a component of fitness prior to field release of the transgenic crop. For parasitoids we placed additional emphasis on potential alterations of the chemical ecology, affecting host finding and acceptance (Pallini et al., Chapter 9, this volume). Plant inputs have a strong driving influence on soil ecosystem processes. Therefore, for these processes, exposure routes, fate and transport of Bt toxins in soils largely determined the kinds of experiments proposed (Mendonça et al., Chapter 10, this volume). Exposure routes in the soil are complex: Bt toxins occur embedded within decaying and living plant material, in root exudates, leakage from broken living roots, and bound on clay and humic substances. A few experiments were proposed for small-scale or largescale field trials (Sujii et al., Chapter 6, this volume), but it will be necessary to 
Table 13.1. The non-target species, species groups and functions prioritized for possible testing of non-target effects of Bt cotton.

\begin{tabular}{|c|c|c|}
\hline Name & & Source \\
\hline \multicolumn{3}{|c|}{ Prioritized in all regions of Brazil } \\
\hline Cotton aphid & Aphis gossypii & Sujii et al., Chapter 6, this volume \\
\hline White fly & Bemisia tabaci & Sujii et al., Chapter 6, this volume \\
\hline Boll weevil & $\begin{array}{l}\text { Anthonomus } \\
\text { grandis }\end{array}$ & Sujii et al., Chapter 6, this volume \\
\hline Fall armyworm & $\begin{array}{l}\text { Spodoptera } \\
\text { frugiperda }\end{array}$ & Sujii et al., Chapter 6, this volume \\
\hline Africanized honey bee & Apis mellifera & Arpaia et al., Chapter 7 , this volume \\
\hline Bumblebee & Bombus sp. & Arpaia et al., Chapter 7 , this volume \\
\hline Green lacewing & $\begin{array}{l}\text { Chrysoperla } \\
\text { spp. complex }\end{array}$ & Faria et al., Chapter 8 , this volume \\
\hline Ladybird beetles & Coccinellidae $^{a}$ & $\begin{array}{l}\text { Faria et al., Chapter } 8 \text {, this volume; } \\
\text { Arpaia et al., Chapter } 7 \text {, this volume }\end{array}$ \\
\hline Egg parasitoid & $\begin{array}{l}\text { Trichogramma } \\
\text { pretiosum }\end{array}$ & Pallini et al., Chapter 9, this volume \\
\hline Larval parasitoid & $\begin{array}{l}\text { Catolaccus } \\
\text { grandis }\end{array}$ & Pallini et al., Chapter 9, this volume \\
\hline $\begin{array}{l}\text { Residue } \\
\text { decomposition }\end{array}$ & & $\begin{array}{l}\text { Mendonça et al., Chapter } 10 \text {, this } \\
\text { volume }\end{array}$ \\
\hline Ammonification & & $\begin{array}{l}\text { Mendonça et al., Chapter } 10 \text {, this } \\
\text { volume }\end{array}$ \\
\hline Nitrification & & $\begin{array}{l}\text { Mendonça et al., Chapter } 10 \text {, this } \\
\text { volume }\end{array}$ \\
\hline Root herbivory & & $\begin{array}{l}\text { Mendonça et al., Chapter 10, this } \\
\text { volume }\end{array}$ \\
\hline Disease transmission & & $\begin{array}{l}\text { Mendonça et al., Chapter 10, this } \\
\text { volume }\end{array}$ \\
\hline Earthworms & Lumbricidae & $\begin{array}{l}\text { Mendonça et al., Chapter } 10 \text {, this } \\
\text { volume }\end{array}$ \\
\hline \multicolumn{3}{|l|}{ High priority regionally } \\
\hline & Bracon vulgaris & Pallini et al., Chapter 9, this volume \\
\hline & Netelia sp. & Pallini et al., Chapter 9, this volume \\
\hline & $\begin{array}{l}\text { Lysiphlebus } \\
\text { testaceipes }\end{array}$ & Pallini et al., Chapter 9, this volume \\
\hline
\end{tabular}

ancluding Cycloneda sanguinea, Hippodamia spp., Coleomegilla maculata, Scymnus spp., Eriopsis spp.

develop the non-target methodology further by specifying the transition from confined testing to field testing.

\section{Gene Flow and Consequences}

All of the gene-flow concerns for Bt cotton in Brazil centre around the fact that the three tetraploid Gossypium species, G. hirsutum, G. barbadense and G. mustelinum, do not have substantial reproductive barriers between 
them, so that all crosses have a high likelihood of producing fertile $\mathrm{F}_{1}$ progeny (Johnston et al., Chapter 11, this volume). There are two major varieties of G. hirsutum in Brazil, G. hirsutum var. latifolium and G. hirsutum var. marie-galante. The first is the typical herbaceous cotton crop, and occurs as cultivated varieties and volunteers. The second is a perennial crop variety that occurs as commercial varieties, land races, volunteers, dooryard plants and in feral populations. There are two major varieties of $G$. barbadense in Brazil, $G$. barbadense var. barbadense and G. barbadense var. braziliense. Both occur as dooryard plants and in feral populations, but only G. barbadense var. braziliense occurs as land races and volunteers. G. mustelinum is a wild species. We concluded from the evidence presented that all of these indigenous Brazilian cottons belong to the primary germplasm pool for Bt cotton, and thus, that hybridization between Bt cotton and indigenous varieties will occur at some frequency. Specifically, there are important gaps in knowledge of the geographical distribution of $G$. barbadense var. barbadense that will be essential to understand before gene-flow risks can be assessed. It will be impossible to eliminate all risk of gene flow from genetically engineered cotton, but it may be possible to reduce the consequences of gene flow, for example, by restricting the area over which $\mathrm{Bt}$ cotton is planted, excluding potential gene-flow 'hotspots'. Whether and where to impose such restrictions in Brazil would depend on the potential consequences of gene flow.

There are many possible consequences of gene flow from $\mathrm{Bt}$ cotton to other Gossypium species in Brazil. The demographic and genetic changes that could occur in G. mustelinum populations as a result of gene flow from $\mathrm{Bt}$ cotton were identified as the most significant potential consequences of gene flow in this system. G. mustelinum is already recognized as rare and potentially endangered in Brazil. Exposure to gene flow might change the genetic composition of the species or create demographic fluctuations that could lead to extinction. While G. mustelinum is the least likely type of recipient population to overlap geographically with Bt-cotton cultivars, there are several ways that genetic bridges between Bt-cotton crops and these wild cotton populations could develop. As a worst-case scenario, repeated gene flow from $\mathrm{Bt}$ cotton (or other elite cotton varieties) could replace the unique genetic character of $G$. mustelinum with crop genes, essentially hybridizing the species out of existence. As a result, the unique germplasm of the species could be lost and the ecological communities in which the plant grows could be altered.

We were unable to thoroughly evaluate several of the other potential consequences of gene flow due to gaps in the knowledge of the biology and ecology of the traditionally cultivated or non-cultivated Gossypium species. Most importantly, we could not evaluate the fitness effect of the Bt gene on cotton fitness outside an agricultural setting because we were missing at least three types of information. First, we do not know if or how much the target insects (cotton leafworm, pink bollworm, cotton budworm and fall armyworm) are feeding on feral, dooryard, volunteer and wild cotton populations. Second, we do not know if plant fitness is affected by target insect herbivore pressure on cotton plants 
outside cultivation. And third, we do not know how the Bt gene will be expressed in a $G$. barbadense or $G$. mustelinum genetic background.

\section{Resistance Risk and Management}

Wherever Bt cotton is deployed, the evolution of resistance in target pests should be viewed as a risk that requires management (Fitt et al., Chapter 12, this volume). Experience with insecticide use and basic consideration of evolutionary theory imply that if a Bt crop were used extensively without any resistance-management intervention, resistance would seem inevitable. We identified four key Lepidopteran targets for deployment of Bt cotton in Brazil: cotton budworm ( $H$. virescens), pink bollworm ( $P$. gossypiella), cotton leafworm (A. argillacea) and fall armyworm (S. frugiperda). The focus of our analysis for Bt cotton in Brazil is to identify pre-emptive strategies to delay the onset of resistance.

A critical factor in defining options for resistance management is the likely exposure of target pests to Bt cotton. Two of the four target species are specialists on cotton bollworm, pink bollworm and cotton leafworm, while cotton budworm is regarded as closely tied to cotton in Brazil. Only fall armyworm is highly polyphagous with a wide range of unrelated host plants. These host relationships would suggest that the three species with close associations with cotton are at greatest risk of resistance from Bt cotton. However, concomitant plans to introduce Bt maize into Brazil invalidate this conclusion, because maize is a significant host for fall armyworm. This species has evolved resistance to a number of insecticide groups and may represent a significant resistance threat across farming systems reliant on Bt crops.

One limitation in our assessment is that comprehensive information was not available on the dose of specific Bt-cotton varieties against any of the target pests in Brazil. A high dose of the Bt toxin, defined as one that kills nearly all susceptibles and $>95 \%$ of heterozygous resistance individuals, will help to delay the onset of resistance in combination with refuge crops. A low dose of the $\mathrm{Bt}$ toxin will require much larger refuges. The possible introduction of Bt maize in Brazil required an assessment of management options for different scenarios involving only $\mathrm{Bt}$ cotton or a combination of $\mathrm{Bt}$ cotton and Bt maize.

While there are many knowledge gaps and research needs, we conclude that it is possible to formulate reasonable recommendations to manage the resistance risk for $\mathrm{Bt}$ cotton in Brazil. Refuge crops are a key component of the recommended strategies for all scenarios. In addition, we strongly recommend that $\mathrm{Bt}$ cotton be deployed as a pyramided two-gene product with both genes expressing a high dose against the same target species. Pyramiding of two independently acting transgenes will provide additional safeguards against resistance, provided refuges are also used.

Overall, our recommendations should serve as a starting point for a comprehensive research and extension effort to fill the many gaps and commence 
the critical task of educating growers about the serious need for resistance management if the potential benefits of $\mathrm{Bt}$ cotton are to be realized and sustained.

\section{Broad Implications of the Case Study}

Conducting this case study provided the authors of the chapters of this book with the opportunity to understand the scientific methods that can be used to support a risk assessment while focusing on a topic of considerable importance and direct relevance to society. In addition, the case study approach was a test for the methodologies described in this book. While most of these methodologies have been proposed in whole or in part in other publications, assembling them all in this single case study enabled authors to gain better appreciation for how science can support risk assessment. This case study, similar to the previously published Kenya case study on Bt maize (Hilbeck and Andow, 2004), revealed many broad findings; we emphasize two of these.

\section{The environmental risks associated with Bt cotton in Brazil will vary among the different regions of Brazil}

Our preliminary assessment of the environmental risks of Bt cotton in Brazil has clarified that non-target gene flow and resistance risks will likely differ among the North-east, Midwest and Meridian regions within Brazil. This means that a risk assessment should be conducted to assess the risks specific to each region rather than being conducted as if the country were a homogeneous whole. Although this may increase the effort needed to complete a risk assessment, such an approach is case-specific as indicated by the Cartagena Protocol and relies on information about the transgene, the crop and the environment where the introduction is planned to occur (NRC, 1987, 2000, 2002; Tiedje et al., 1989; EU, 2001; Snow et al., 2005). This region-specificity also means that risk management can be tailored to the region, with different risk-management approaches for each region, allowing for more flexibility in management, as has been suggested for gene-flow risks (Johnston et al., Chapter 11, this volume) and resistance risks (Fitt et al., Chapter 12, this volume). This flexibility could result in a lower cost for risk management.

While there is also likely to be significant variation in environmental risk within each of these regions, conducting risk assessment at finer spatial scales may not improve environmental safety. Within each region, environmental risks may be related to variation in farm size and management, with largescale monoculture having greater resistance risk than small-scale diversified production systems. However, stratifying risk assessment within regions, such as by farm size and management practice or by habitat heterogeneity would likely create an unduly complex risk-assessment process that could make risk management very difficult. Finding and implementing a socially desirable riskmanagement policy in a stratified social environment or a fine-scale spatial environment could be extremely complex. 
NORTH-EAST REGION. Considerable environmental variability and physiological stress to cotton in this region may affect transgene expression. Gene flow to other Gossypium plants may be likely. G. hirsutum var. marie-galante, G. barbadense and G. mustelinum are present and could be affected. Farming is done on a small spatial scale and productivity is low for Brazil, but about half of the farmers and farming families in cotton in Brazil are in this region. Effective resistance management may be difficult because of the small scale of farming. Population changes to cotton boll weevil need careful assessment because it is a key pest and most farmers in the region cannot afford increased control costs should boll weevil become a more important pest. Other non-target species may be characteristic to this region and require their own assessment. Benefits of Bt cotton to small-scale farmers could be significant if pesticide applications can be reduced.

MIDWEST REGION. Large-scale production predominates and yields are high in this region. Production is new to this region in the past 5-10 years and continues to expand. Gene flow could occur to $G$. barbadense and mainly to other commercial cotton lines, and is therefore a less significant concern than in the North-east. Effective resistance management may be most easily realized in this region, because the scale of production is so large and farmers can internalize both the costs and benefits of resistance management. However, one of the key Lepidopteran pests is fall armyworm, which may require a large refuge of non-Bt cotton for effective resistance management. The simplified, large-scale agricultural production systems embedded in the unique and biologically diverse Cerrado landscapes result in a relatively unknown, but characteristic, non-target flora and fauna. It will be necessary to assess the possible risks of $\mathrm{Bt}$ cotton to this unique flora and fauna.

MERIDIAN REGION. Small- to large-scale production predominates, and cotton yields can be high, although not as high as in the Midwest. Gene flow may occur to other commercial cotton lines and possibly to G. barbadense, and is therefore a less significant concern than in the North-east and similar to the Midwest. Effective resistance management may be possible in this region, in part because of the diversified cropping systems. The scale of production is large enough that individual farmers may be able to implement effective resistance management. The landscapes are less uniform than in the Midwest, but the non-target fauna in cotton is better known than in the Midwest.

AMAZON REGION. At present, this region has little cotton production, and possible environmental risks in this region were not assessed in this case study. Cotton production is increasing in the borders of this region, so risk assessment may become necessary in the future. The Amazon region harbours wild relatives of G. hirsutum that could be adversely affected by gene flow.

We identified and prioritized the potential adverse effects to the environment and associated data gaps, and developed some protocols to address these issues. Our methods can be used to support environmental risk assessment of transgenic crops scientifically and transparently as required by the Protocol on Biosafety (Annex III). 
Developing, adapting and using the methodologies in this book will enable a country such as Brazil to support a risk-assessment process that would meet its obligations under the Protocol on Biosafety. We have developed efficient and transparent scientific procedures to select from the high diversity of possible non-target species a much smaller number of species that could serve as test organisms to support non-target risk assessment (non-target selection matrices). We have developed straightforward methods for identifying potential recipients and adverse effects of gene flow, and for assessing resistance risk. All of these methodologies are initiated on a case-by-case basis as suggested by the protocol.

We recognize that the Cartagena Protocol allows for the use of a precautionary approach to decision making, but have focused our efforts on appropriate methods for addressing scientific uncertainty. We have developed scientific, transparent methods that can be layered on top of our main methodologies so that the influence of scientific uncertainty on the interpretation of results can be clarified. In general, we have relied on evaluating worst-case scenarios to clarify the influence of scientific uncertainty. We believe that it is important that scientific, transparent methods for addressing uncertainty are available to be incorporated, as appropriate, into the decision-support process.

We also developed a temporal staging of the scientific methodologies to correspond with the stages of development of a transgenic plant, starting from the transformation of cell lines to the release of a commercial product. Staging the scientific evaluations in this way allows the risk-assessment process to proceed in a timely manner, so that its quality is not compromised by unnecessarily shortened timelines, and it does not require more work than necessary. We suggest that during pre-commercial assessments, three levels of evaluation are probably needed:

- Laboratory and greenhouse

- Small-scale field trials

- Large-scale field trials

We suggest that the Brazilian regulatory system should be modified to allow large-scale field testing prior to commercial approval, because several elements of the risk-assessment process will require large-scale testing.

An additional significant result was the improved scientific capacity to conduct research on the environmental risks of transgenic crops in Brazil. By focusing on potential environmental risks of Bt cotton, a broad spectrum of Brazilian agricultural scientists now understand how to apply their research skills to conduct experiments to support the assessment of environmental risks of transgenic crops.

Some of the research gaps identified in this book have already been started to be filled in Brazil. Studies are being carried out to gather baseline data on flower-visiting insects in the Midwest and North-east, and have already revealed a strikingly higher diversity than was expected from the scientific literature, for instance five bee species had been identified from the literature, whereas 40 were sampled (E. Fontes, Brasilia, Brazil, 2004, personal communication). Moreover, the survey found strong regional differences; in the 
Midwest 23 species were surveyed and in the North-east 21 species were surveyed, but only four of these species were found at both sites. Scientists are investigating the Spodoptera biotypes on maize and cotton in the Midwest and have found them to be the same (C. Omoto, Piracicaba, Brazil, 2004, personal communication). A group is quantifying hybridization rates within and between cotton fields with certain separation distances and barrier crops, using glandless cotton as a marker, and also carrying out in situ characterization of wild, feral, dooryard and local varieties (Barroso et al., 2004).

\section{Recommendations and Future Outlook}

The potential commercial release of $\mathrm{Bt}$ cotton in Brazil proved to be an instructive and challenging case, as illustrated by each chapter of this book. Cotton is an income source both for subsistence farmers of the North-east region and for large-scale agribusiness in the Midwest and Meridian regions. As highlighted by the PFOA (Capalbo et al., Chapter 3, this volume), this provides vastly different contexts for understanding the potential utility and risks of Bt cotton. Brazil is one of the centres of diversification of cotton, and the cotton plant supports a rich fauna of herbivores and carnivores. This diversity of species, habitats and socio-economic conditions offered an array of options and a rich background for the evaluations evident in this book.

Consequently, this book offers the reader insights into how science can support environmental risk-assessment of one complex case of a transgenic crop. In so doing, it also offers the scientists, regulators and educators a rich source of information and methodologies to help identify possible adverse environmental effects, formulate hypotheses to evaluate the likely occurrence of possible environmental risks and plan appropriate scientific experiments to test these hypotheses. For regulatory personnel, it can be used as a tool to support decision making. While these methodologies can assist and support decision making, they will not replace the judgements and balancing of interests that decision makers must address.

It became clear that the baseline information needed to support environmental risk assessment in Brazil is in part unorganized or weak. Existing information needs to be systematically reviewed and made readily available, as demand requires. In addition, new data are needed to address important informational gaps. These data needs must be prioritized in funding programmes launched by the funding agencies. Moreover, as the assessment of pest resistance risk showed, there is a crucial and urgent need for farmer education and information programmes, particularly for insect-resistant transgenic crops.

It was also clear that scientific support of environmental risk assessment of transgenic crops in Brazil will require the involvement of a wide range of expertise. We identified a need to deepen the understanding of risk assessment and to engage more scientists in research in this area, so that scientists can more quickly provide targeted data needed to assess and manage risks. This can be encouraged by introducing the topic of environmental risk assessment in the programmes of scientific meetings, developing and conducting training 
courses and creating funding opportunities for risk assessment-related research. Although Brazil has the second largest agricultural research infrastructure in the world, there is a need to focus the research and development capacity in the country and to continue close collaboration and interchange with scientists from countries where risk-assessment research has a longer history.

We recommend that the methodologies developed in this book are consolidated in Brazil and expanded to other Latin American countries. This can be accomplished by developing course materials and offering training courses in these countries. The first audience of these training courses should be scientists or regulators who would be able to disseminate the methods to more people, i.e. priority should be given to training the trainers who can then teach others within their respective countries. Through these processes, we can face the challenges of how to characterize the risks and uncertainties to be useful for and understandable by decision makers.

\section{References}

Andow, D.A. and Hilbeck, A. (2004) Science-based risk assessment for non-target effects of transgenic crops. BioScience 54, 637-649.

Andow, D.A., Somers, D.A., Amugune, N., Aragão, F.J.L., Ghosh, K., Gudu, S., Magiri, E., Moar, W.J., Njihia, S. and Osir, E. (2004) Transgene locus structure and expression of $\mathrm{Bt}$ maize. In: Hilbeck, A. and Andow, D.A. (eds) Environmental Risk Assessment of Transgenic Organisms: A Case Study of Bt Maize in Kenya. CAB International, Wallingford, UK, pp. 83-116.

Barroso, P.A.V., Ciampi, A.Y., Hoffmann, L.V., Costa, J.N., Freire, E.C., Andrade, F.O., Carvalho, L.P. and Vidal Neto, F.C. (2004) Gene flow in cotton in Brazil. Poster shown at 8th International Symposium on the Biosafety of Genetically Modified Organisms, 26-30 September 2004, Montpellier, France.

Birch, A.N.E., Wheatley, R., Anyango, B., Arpaia, S., Capalbo, D., Getu Degaga, E., Fontes, E., Kalama, P., Lelmen, E., Lövei, G., Melo, I.S., Muyekho, F., Ngi-Song, A., Ochiendo, D., Ogwang, J., Pitelli, R., Sétamou, M., Sithanantham, S., Smith, J., Son, N.V., Songa, J., Sujii, E., Tan, T.Q., Wan, F.-H. and Hilbeck, A. (2004) Biodiversity and non-target impacts: a case study of Bt maize in Kenya. In: Hilbeck, A. and Andow, D.A. (eds) Environmental Risk Assessment of Transgenic Organisms: A Case Study of Bt Maize in Kenya. CAB International, Wallingford, UK.

Capalbo, D.M.F. and Fontes, E.M.G. (2004) GMO Guidelines Project, Algodão Bt. Embrapa Document 38, Embrapa Meio Ambiente, Jaguariúna, SP, Brazil. Available at: http://www.cnpma.embrapa.br/download/documentos_38.pdf

Corrêa, R.L., Silva, T.F., Araújo, J.L.S., Barroso, P.A.V., Vidal, M.S. and Vaslin, M.F.S. (2005) Molecular characterization of a virus from the family Luteoviridae associated with cotton blue disease. Archives of Virology 157(30), 1357-1367.

EU (European Union) (2001) Regulation of the European Parliament and of the Council on genetically modified food and feed. EC 2001/18. Available at: http://europa.eu.int/eur-lex/en/com/pdf/2001/en_501PC0425.pdf 
Hilbeck, A. and Andow, D.A. (eds) (2004) Environmental Risk Assessment of Transgenic Organisms: A Case Study of Bt Maize in Kenya. CAB International, Wallingford, UK, $281 \mathrm{pp}$.

Nelson, K.C., Kibata, G., Lutta, M., Okuro, J.O., Muyekho, F., Odindo, M., Ely, A. and Waquil, J. (2004) Chapter 3: Problem formulation and options assessment (PFOA) for genetically modified organisms: the Kenya case study. In: Hilbeck, A. and Andow, D.A. (eds) Risk Assessment of Transgenic Crops: A Case Study of Bt Maize in Kenya. CAB International, Wallingford, UK, pp. 57-82.

NRC (National Research Council) (1987) Field Testing Genetically Modified Organisms: Framework for Decisions. National Academy Press, Washington, DC.

NRC (National Research Council) (2000) Genetically Modified Pest-Protected Plants: Science and Regulation. National Academy Press, Washington, DC.

NRC (National Research Council) (2002) Environmental Effects of Transgenic Plants: the Scope and Adequacy of Regulation. National Academy Press, Washington, DC.

Snow, A.A., Andow, D.A., Gepts, P., Hallerman, E.M., Power, A., Tiedje, J.M. and Wolfenbarger, L.L. (2005) Genetically modified organisms and the environment: current status and recommendation. Ecological Applications 15(2), 377-404.

Tiedje, J.M., Colwell, R.K., Grossman, Y.L., Hodson, R.E., Lenski, R.E., Mack, R.N. and Regal, P.J. (1989) The planned introduction of genetically engineered organisms: ecological considerations and recommendations. Ecology 70, 298-315. 